\title{
Infantilization of adolescents in the digital environment
}

\author{
Vladimir N. Panferov ${ }^{1}$, Svetlana A. Bezgodova ${ }^{1}$, and Anastasia V. Miklyaeva ${ }^{1, *}$ \\ ${ }^{1}$ Herzen State Pedagogical University of Russia, Institute of Psychology, 191186, Saint Petersburg, \\ Russia
}

\begin{abstract}
The article presents the results of studying the personal maturity of adolescents aged 13-17 $(n=1078)$ who are infantilized in intergenerational relationships (on the model of relations with parents and teachers). Empirical data were collected with the use of the Self-Assessment Scale of Personal Maturity, as well as the modified Dembo-Rubinstein Self-Assessment Diagnostic Method, which measured the actual self-assessment of adolescents' adulthood, as well as reflected assessments of their own adulthood from the parents' and teachers' positions. Infantilization in intergenerational relationships was assessed by comparing the selfassessment of adulthood and the reflected assessments of parents and teachers. The results show that the relationships between adolescents, on the one hand, and parents and teachers, on the other hand, are characterized by a tendency to infantilization. Obvious infantilization is found in about $10 \%$ of cases. Infantilization in intergenerational relationships affects, first of all, the regulatory maturity of adolescents, and its influence differs depending on who is the subject of infantilization: in the case of infantilization by parents, the regulatory maturity of adolescents decreases as they grow up, while in the case of infantilization by teachers it increases. In general, infantilization in relations with parents has more intense negative impact on the formation of personal maturity in adolescence, in comparison with infantilization on the part of teachers.
\end{abstract}

\section{Introduction}

In modern society, older adolescence is considered as the initial stage of the formation of some personal qualities which could be called the "mature personality". Therefore, the study of the factors that determine the "personal maturity" of adolescents is undoubtedly relevant for solving a wide range of theoretical and practical problems. However, such studies are complicated by the fact that the category "personal maturity" does not have an unambiguous interpretation and correlates with different levels of personality organization: from psychophysiological [1] to social [2] with mental [3], psychological [4] and sociopsychological[5; 6] levels between. Some researchers identify "personal maturity" as one of these levels [7], while the others distinguish it as an independent phenomenon [8]. In all cases, the criteria for "personal maturity" are debatable. Their interpretation involves the development and implementation of social roles corresponding to social expectations [9], as

\footnotetext{
*Corresponding author: a.miklyaeva@gmail.com
} 
well as the description of personal characteristics that are formed in different periods of human development and allow a person to successfully realize his/her potential in adulthood [8]. The behavior of a mature person is autonomous, motivated by conscious motives [10]. Maturity implies the acquisition of a positive identity, which, in turn, is determined by the consistent inclusion of a person in various social communities, giving a subjective sense of belonging to them, and by the formation of a sense of the own life from the social point of view [11]. In adolescence, the formation of personal maturity occurs in the processes of constructing the image of adulthood [3], which reflects the characteristics of the regulatory, reflexive, cognitive and moral potential of the individual [12].

The analysis of the phenomenon of personal maturity inevitably involves an appeal to the category of "personal infantilism", which is the opposite (in relation to personal maturity) pole of the social construct used to normalize the results of a person's development of social roles corresponding to the current age and stage of life, as well as to determine the personal prerequisites for success in social relations [12]. In this regard, it can be assumed that one of the factors that could influence the formation of personal maturity in adolescence is infantilizing relationships with the other people, primarily those who make up the circle of "significant others".

An infantilizing relationship can be defined as a relationship that aims at forming or prolonging an infantile state in a person by treating him or her as a child. The essence of infantilization is to create conditions in which the expectations regarding the behavior of people who have come out of childhood are more or less close to the social concepts that fix the expectations regarding children's behavior [13]. Today, infantilizing practices are considered as an inevitable consequence of the juvenilization of society [14], the tendency to bring the world of children and the world of adults closer together [15], and the loss of the status of absolute value by adulthood [16]. One of the possible reasons for the described trends is associated with the change of intergenerational relationships between people [17], as well as with the change of identification standards and the growing anxiety of noncompliance with the expected image of the "adult" which determines attempts to counter it by constructing an alternative way of life [18]. In accordance with the logic of socio-age development, as the greatest burden associated with achieving compliance with the criteria of "personal maturity" falls on the periods of youth and early adulthood, we can assume that the first manifestations of the influence of infantilizing relationships on the formation of personal maturity will be revealed in adolescence. Moreover, it is possible to suggest that this trend will probably be most clearly traced in intergenerational relationships, which represent "identification standards of adulthood" for adolescents. Taking into account the data available in the literature on the system of social relations of modern adolescents [19], we consider their parents and teachers as potential subjects of their infantilization in intergenerational relations.

\section{The present study}

Thus, the aim of the study was to analyze the age dynamics of personal maturity of adolescents who are infantilized in intergenerational relationships (on the example of relationships with parents and teachers).

The study focused on the following research questions:

1) What is the age dynamics of the indicators of personal maturity in adolescenct in the age range of 13-17 years old?

2) What contribution does the infantilization of adolescents in intergenerational relationships make to the formation of their personal maturity?

The research involved 1078 adolescents aged 13-17 (63.1\% of girls) living in five regions of Russia, students of schools and secondary special educational institutions. Participation in 
the study was voluntary. The program and protocol of the study were approved by the Ethics Committee of Herzen State Pedagogical University of Russia (Protocol No.19 of 26.01.2021). The empirical data were collected with the use of the online service Google Forms.

\section{Method}

The personal maturity of adolescents was assessed with the use of the Self-Assessment Scale of Personal Maturity. The scale is designed to identify the self-assessments of the individual in relation to the standards of personal maturity that make up the content of the social construct "personal maturity - personal infantilism". The aim of the Scale is to evaluate the degree of compliance of the respondent's self-image with the reference requirements for a "mature personality". The main indicator is the self-assessment of the compliance of the current level of personal development with the content of normative ideas about the "mature personality". The Scale includes four subscales: regulatory maturity, moral maturity, cognitive maturity and reflexive maturity. The range of ratings for each subscale is from 4 to 28 points, and the total score is from 16 to 112 points. The scale has satisfactory psychometric characteristics and is successfully used in studies on adolescent samples [12].

Infantilization in intergenerational relationships was studied using a modified DemboRubinstein Self-assessment diagnostic technique. Respondents were offered "Child - Adult" scales, where they were required to mark their "real Self" from three evaluation positions: "Myself", "parents", and "teachers" (grades range from 0 to 10). Then the difference between the self-assessment and the reflected assessments of parents and teachers was calculated (range - from -10 to 10). Intergenerational relationships were recognized as infantilizing if the difference in estimates exceeded the range of normative values calculated on this sample $(\mathrm{M} \pm \sigma)$. A similar research procedure was used in our previous studies, where it showed its productivity and reliability [12].

Statistical processing of the results was carried out using the statistical software package Statictica10.0 and included the calculation of descriptive statistics $(\mathrm{M} \pm \sigma)$, the Student's Ttest for dependent samples $(\mathrm{t})$, as well as ANOVA analysis of variance $(\mathrm{F})$.

\section{Results}

The results show that the indicators of personal maturity in the age range of 13-17 years remain stable. The analysis of variance did not reveal significant differences in the indicators, which were obtained in the samples of adolescents of different ages. Adolescents rate their reflexive maturity slightly higher and, on the contrary, their regulatory, moral, and cognitive maturity lower (see Table 1). This trend is the same for the samples of boys and girls, despite the fact that girls generally rate their reflexive maturity higher than boys $(\mathrm{F}=6.19, \mathrm{p}<0.01)$, and boys, in turn, rate their own regulatory maturity higher than girls $(\mathrm{F}=7.68, \mathrm{p}<0.01)$.

Table 1. Age dynamics of personal maturity indicators in adolescents.

\begin{tabular}{|l|c|c|c|c|c|}
\hline $\begin{array}{c}\text { Indicators of personal } \\
\text { maturity }\end{array}$ & $\begin{array}{c}\mathbf{1 3} \text { years old } \\
(\mathbf{M} \pm \mathbf{S})\end{array}$ & $\begin{array}{c}\mathbf{1 4} \text { years old } \\
(\mathbf{M} \pm \mathbf{S})\end{array}$ & $\begin{array}{c}\mathbf{1 5} \text { years old } \\
(\mathbf{M} \pm \mathbf{S})\end{array}$ & $\begin{array}{c}\mathbf{1 6} \text { years old } \\
(\mathbf{M} \pm \mathbf{S})\end{array}$ & $\begin{array}{c}\mathbf{1 7} \text { years old } \\
(\mathbf{M} \pm \mathbf{S})\end{array}$ \\
\hline Reflexive maturity & $18.72 \pm 3.68$ & $18.24 \pm 3.78$ & $17.81 \pm 3.77$ & $17.64 \pm 4.06$ & $17.97 \pm 3.69$ \\
\hline Regulatory maturity & $14.29 \pm 3.33$ & $14.32 \pm 3.59$ & $14.10 \pm 3.29$ & $14.37 \pm 3.47$ & $14.41 \pm 3.59$ \\
\hline Moral maturity & $15.09 \pm 3.43$ & $15.11 \pm 2.92$ & $15.15 \pm 3.27$ & $14.55 \pm 3.15$ & $15.22 \pm 3.17$ \\
\hline Cognitive maturity & $14.54 \pm 3.68$ & $14.11 \pm 3.43$ & $14.28 \pm 3.09$ & $14.06 \pm 3.17$ & $14.86 \pm 3.84$ \\
\hline Total indicator & $62.64 \pm 9.94$ & $61.78 \pm 9.15$ & $61.33 \pm 9.20$ & $60.62 \pm 9.59$ & $62.46 \pm 9.95$ \\
\hline
\end{tabular}


However, the self-assessment of one's own adulthood is expected to increase as adolescents grow older $(\mathrm{F}=3.67, \mathrm{P}<0.01)$, while the reflected assessments of parents and teachers remain relatively stable, and, in addition, these assessments are significantly lower than the self-assessments of adolescents $(\mathrm{t}=8.12, \mathrm{p}<0.001$ for comparing the reflected selfassessments and assessments of parents; $\mathrm{t}=5.53, \mathrm{p}<0.01$ for comparing the reflected selfassessments and assessments of teachers), see Figure 1. At the same time, the reflected ratings of parents are significantly lower than the reflected ratings of teachers (at $\mathrm{t}=2.86, \mathrm{p}<0.01$ ).

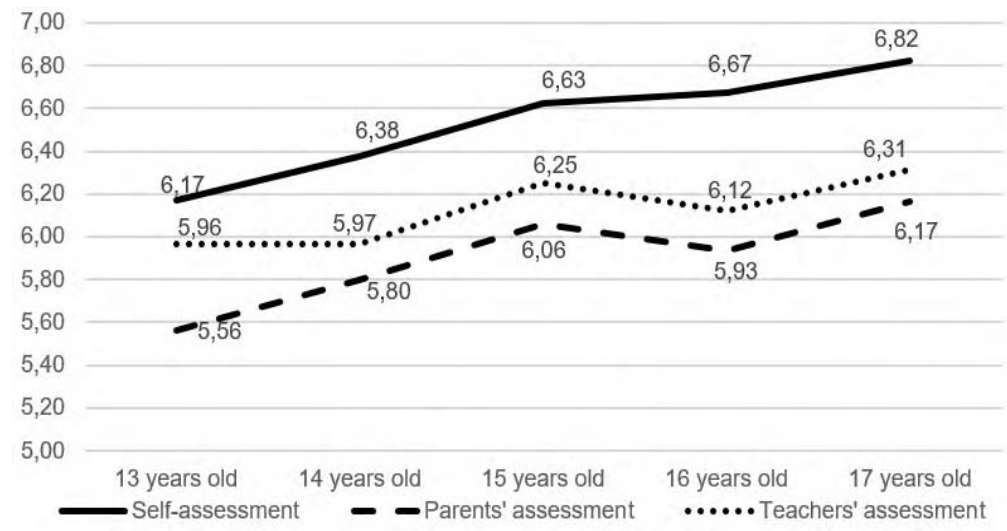

Fig. 1. Age dynamics of self-assessment and reflected assessments of adulthood.

Indicators of infantilization in intergenerational relationships have shown stability over the studied age period (see Table 2). Positive values of the indicators highlights that the tendency to infantilization in intergenerational relationships prevails over the tendency to overestimate the maturity in adolescence (54.78\% for relationships with parents and $51.10 \%$ for relationships with teachers). At the same time, $10.39 \%$ of adolescents noted intense infantilization in relations with their parents, and $7.39 \%$ - in relations with teachers.

Table 2. Age dynamics of indicators of infantilization in intergenerational relationships.

\begin{tabular}{|l|c|c|c|c|c|}
\hline $\begin{array}{c}\text { Indicators of } \\
\text { infantilization }\end{array}$ & $\begin{array}{c}\mathbf{1 3} \text { years old } \\
(\mathbf{M} \pm \mathbf{S})\end{array}$ & $\begin{array}{c}\mathbf{1 4} \text { years old } \\
(\mathbf{M} \pm \mathbf{S})\end{array}$ & $\begin{array}{c}\mathbf{1 5} \text { years old } \\
(\mathbf{M} \pm \mathbf{S})\end{array}$ & $\begin{array}{c}\mathbf{1 6} \text { years old } \\
(\mathbf{M} \pm \mathbf{S})\end{array}$ & $\begin{array}{c}\mathbf{1 7} \text { years old } \\
(\mathbf{M} \pm \mathbf{S})\end{array}$ \\
\hline Infantilization by parents & $0.61 \pm 2.50$ & $0.58 \pm 2.56$ & $0.57 \pm 2.16$ & $0.74 \pm 2.42$ & $0.65 \pm 3.19$ \\
\hline Infantilization by teachers & $0.21 \pm 2.51$ & $0.43 \pm 2.51$ & $0.37 \pm 2.40$ & $0.55 \pm 2.42$ & $0.51 \pm 2.86$ \\
\hline
\end{tabular}

The results of variance analysis allow us to conclude that the indicator of regulatory maturity is the most sensitive to infantilizing intergenerational influences in adolescence. At the same time, the infantilizing effects of parents and teachers have different impact on regulatory maturity: infantilization in relations with parents contributes to a decrease in regulatory maturity in the period of 16-17 years old, while infantilization in relations with teachers, on the contrary, increases it. However, adults' overestimation of the level of adolescent maturity in all cases is associated with a decrease in the indicators of adolescents' regulatory maturity as they grow up, in the period of 16-17 years old (see Figures 2 and 3). 


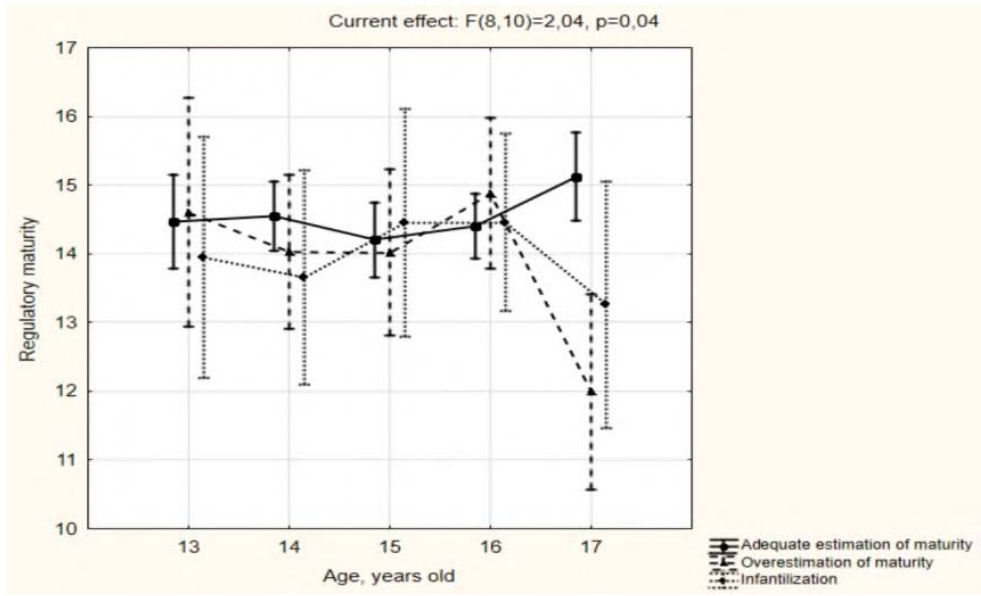

Fig. 2. Age dynamics of regulatory maturity in adolescents with different levels of infantilization in relationships with parents.

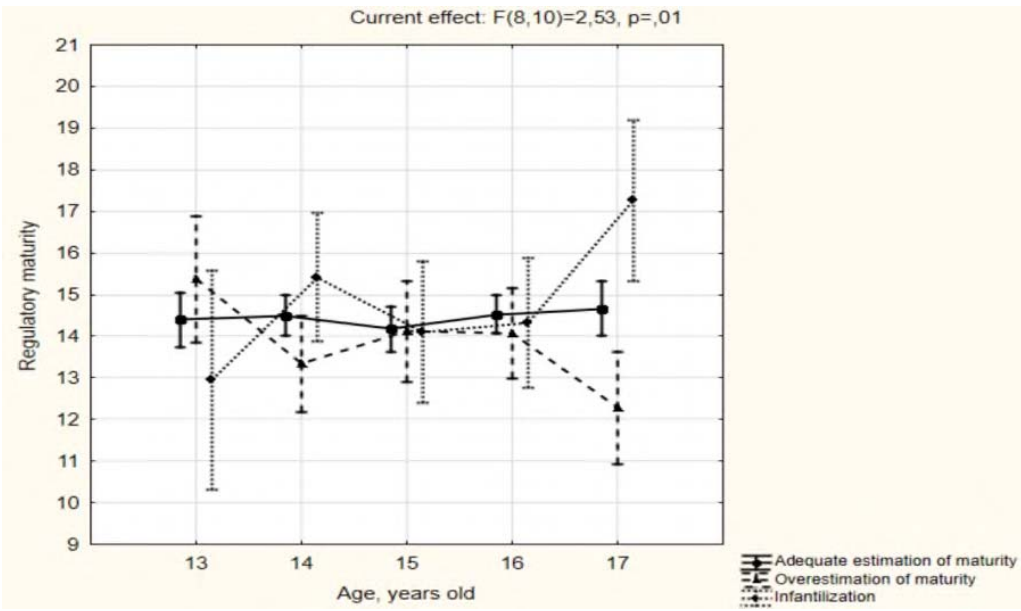

Fig. 3. Age dynamics of regulatory maturity in adolescents with different levels of infantilization in relationships with teachers.

Gender-specific features of the age dynamics of personal maturity indicators in adolescents with different levels of infantilization in intergenerational relationships were not found.

\section{Discussion}

In accordance with the first research question, we have analyzed the age dynamics of personal maturity indicators in older adolescence (13-17 years old). The results showed that the indicators of personal maturity in this age range remain stable, and there is no positive or negative age dynamics. In the structure of personal maturity characteristics, adolescents evaluate their reflexive maturity higher than all other components. It means that they consider themselves as a whole able to adequately self-assessment, to assessment their actions and their consequences. At the same time, the rates of regulatory, moral and cognitive maturity are lower. This tendency indicates some doubts among adolescents about their abilities to manage their behavior, make independent decisions and be responsible for their 
consequences, build their behavior in accordance with the requirements of moral norms, and productively use their own life experience to solve current problems. The found gender differences (higher scores of reflexive maturity in the sample of girls and higher scores of regulatory maturity in the sample of boys) are most likely a reflection of the gender-specific trajectories of growing up, due to differences in the expectations for the behavior of "adult men" and "adult women" [20].

Further analysis showed that despite the lack of dynamics in the indicators of personal maturity in the sample of adolescents from 13 to 17 years, there is a consistent and intense increase in the indicators of their self-assessment of adulthood, which is not supported by the expected increase in the reflected assessments of adulthood attributed by adolescents to parents and teachers. This fact indicates the predominance of infantilizing tendencies in the relations of adolescents with older generation (in our case with parents and teachers), which is persistent throughout the adolescence. Manifestations of infantilization in intergenerational relationships were noted by about half of adolescents, and every tenth adolescent noted intense manifestations of infantilization. The results of our study suggest that the manifestations of adolescent infantilization in relations with parents are significantly more intensive than infantilization in relations with teachers, which confirms the assumption of our previous studies that in adolescence the most significant contribution to infantilization is made by the relationship with parents [12].

The results of variance analysis confirm the hypothesis that infantilization in intergenerational relationships contributes to the formation of personal maturity. It turned out that this contribution is reflected, first of all, in the change in the age dynamics of regulatory maturity: adolescents who experience infantilizing relationships on the part of their parents are characterized by a decrease in their ability to manage their own behavior, make independent decisions and take responsibility for their consequences, which is manifested in the age range of 16-17 years old. These results are correlated with the data of other studies, which suggest that in adolescence is typically the most obvious gap between the awareness of new opportunities and the lack of self-regulation [21], as well as with the information about the decisive contribution of parental relations to the formation of adolescents' regulatory potential $[22 ; 23]$. At the same time, infantilization by teachers, on the contrary, leads to an increase in adolescents'self-esteem of their own regulatory possibilities. Probably, these differences are explained by the various significance of parents and teachers as subjects of infantilization in intergenerational relations, which allows adolescents to resist the infantilizing influences of teachers to a greater extent than those of parents, and in some cases use them as a resource for their own development. The infantilizing influences of parents, in turn, have a more significant impact on the formation of personal maturity of adolescents, presumably due to the fact that modern adolescents are largely dependent on their parents, and parental care often takes the form of control and suppression of the will [24].

An additional finding of our study, which is not relevant to the main research aim, was a negative influence of overestimation of adolescents' adulthood by representatives of the older generation on the regulatory maturity in adolescence. Probably, this tendency is determined by an excessive "volume" of freedom for adolescents, which they cannot use productively for the benefit of their personal development. This hypothesis, however, needs further empirical testing. In general, these data point to the prospect of a detailed study aimed at analyzing the contribution of the assessment of adolescents' adulthood by representatives of the older generation to their personal maturity, as well as to other indicators of personal development. 


\section{Conclusion}

Infantilization in intergenerational relationships is manifested in the underestimation of the degree of adolescents' adulthood by the representatives of older generations. Today infantilization is a typical model of the relations of the older generation to adolescents, which is recognized in various degrees by more than half of the respondents. Infantilization in intergenerational relationships primarily affects the regulatory maturity of adolescents. The influence of infantilization in intergenerational relations on the formation of personal maturity of adolescents does not depend on the gender of the adolescents but it differs due to the subject of infantilization: infantilization on the part of parents contributes to decrease in the regulatory maturity, while infantilization on the part of teachers, on the contrary, to increase. The age range for these effects' manifestation is 16-17 years old. At the same time, infantilization in relations with parents has a more intense negative impact on the formation of personal maturity of adolescents, in comparison with infantilization on the part of teachers. Further research in the field of studying the influence of infantilizing intergenerational relations on the formation of the personality in adolescence could become the basis for solving one of the most important problems of modern society - overcoming the manifestations of infantilism in adolescence and youth. The results of our research could contribute to the development of effective programs aimed at psychological and pedagogical support for personal development in adolescence.

\section{Acknowledgements}

The research was supported by the Ministry of Education of the Russian Federation as part of a state task (project No. FSZN-2020-0027).

\section{References}

1. Dubrovinskaya, N. V., Farber, D. A., Bezrukikh, M. M.: Psikhofiziologiya rebenka: psikhofiziologicheskie osnovy detskoy valeologii. Vlados, Moscow (2000).

2. Soldatchenko, A. L.: Kharakteristika sotsial'noy zrelosti lichnosti s pozitsiy interaktivnogo podkhoda. Bulletin of the South Ural State University. Series "Education. Educational sciences", 14 (273), 80-85 (2012).

3. Vygotskiy, L. S.: Sobranie sochineniy: V 6-ti t. T.3. Problemy razvitiya psikhiki. Pedagogika, Moscow (1983) (In Russ).

4. Petrovskiy, A. V., Yaroshevskiy, M. G.: Osnovy teoreticheskoy psikhologii. INFRA-M, Moscow (1998) (In Russ).

5. Zhuravlev, A. L.: Sotsial'no-psikhologicheskaya zrelost': obosnovanie ponyatiya. Psikhologicheskiy zhurnal, 28 (2), 44-55 (2007).

6. Leonov, N. I., Glavatskikh, M. M.: Sotsial'no-psikhologicheskaya zrelost' lichnosti: integrativnyy podkhod. Izvestiya of Saratov University, 14 (1), 55-60 (2014).

7. Rean, A. A.: Psikhologicheskie problemy akmeologii. Akmeologiya lichnosti. Psikhologicheskiy zhurnal, 3, 88-95 (2000).

8. Bodalev, A. A.: Vershiny v razvitii vzroslogo cheloveka. Piter, Saint-Petersburg (2007) (In Russ).

9. Anan'ev, B. G.: Chelovek kak predmet poznaniya. Izd-vo LGU, Leningrad (1968) (In Russ).

10. Allport, G.: Stanovlenie lichnosti: Izbrannye trudy. Smysl, Moscow (2002) (In Russ). 
11. Erikson, E.: Identichnost': yunost' i krizis. Progress, Moscow (1996) (In Russ).

12. Miklyaeva, A. V.: Lichnostnyi infantilizm v postindustrial'nom obshchestve. Sotsial'nopsikhologicheskii podkhod $\mathrm{k}$ probleme infantilizatsii lichnosti $\mathrm{v}$ usloviyakh sovremennoi sotsial'noi deistvitel'nosti. LAMBERT Academic Publishing, Dyussldorf (2018).

13. Miklyaeva, A. V.: The infantilization of the elderly in everyday interaction: problem statement. The journal of social policy studies, 1 (6), 109-124 (2018). DOI: 10.17323/727-0634-2018-16-1-109-124

14. Postman, N.: The Disappearance of Childhood. Random House, N. Y. (1982).

15. Bernardini, J.: The Infantilization of the Postmodern Adult and the Figure of Kidult. Postmodern Openings, 5 (2), 39-55 (2014).

16. Mayorova-Shcheglova, S. N., Mitrofanova, S. Yu.: Early maturation or infantilization: The paradox of modern childhood events. Vestnik of Saint Petersburg University. Sociology, 13 (1), 25-39 (2020). DOI: 10.21638/spbu12.2020.102

17. Calcutt, A.: Arrested Development: Pop Culture and the Erosion of Adulthood. Cassell, London (1998).

18. Aline, M.: Reevaluating the concept of adulthood and the framework of transition. Journal of youth studies, 17 (3), 415-429 (2014).

19. Undusk, E. N.: A comparative study of subjective conditions for introspection in school students experiencing problems in various areas of life. Psychology in Education, 1 (2), 117-125 (2019). DOI: 10.33910/2686-9527-2019-1-2-117-125

20. Cunningham, M., Beutel, A., Barber J., Thornton, A.: Reciprocal relationships between attitudes about gender and social contexts during young adulthood. Social Science Research, 34, 862- 892 (2005). DOI:10.1016/J.SSRESEARCH.2005.03.001

21. Steinberg, L., Icenogle, G., Shulman, E. P., Breiner, K. et al.: Around the world, adolescence is a time of heightened sensation seeking and immature self-regulation. Developmental Science, 21 (2), 1-N (2018). DOI: 10.1111/desc.12532

22. Dash, S. S., Verma, S. K.: A psycho-social study on the role of parenting and emotional regulation on intergenerational support: An youth perspective. Indian Journal of Positive Psychology, 8 (4), 591-597 (2017).

23. Sindhu, V., Jain, V.: Parenting style and emotional maturity among adolescents across gender. Indian Journal of Health and Well-being, 11 (7-9), 311-314 (2020).

24. Petrenko, T. V., Sysoyeva, L. N.: Family influence on youth infantilization in the transformation of the modern Russian society. Family and personality: Problems of interaction, 5, 90-97 (2016) (In Russ). 